\title{
Tools for Transformation - How Engineering Education benefits from inter- active e-learning and the Humanities
}

\section{Dr. Katarina Larsen, KTH - Royal Institute of Technology}

Katarina Larsen, researcher at KTH - Royal Institute of Technology, Sweden. Experience from teaching and course development in Engineering Education at Masters level and graduate courses level in areas of Organizational Studies. Ongoing research interests includes studies of institutional change, science and innovation policy, and sustainability in engineering education.

\section{Mr. Johan Gustav Gärdebo, KTH Royal Institute of Technology}

Johan Gärdebo is a PhD Candidate in History of Technology and Environment, studying how technological systems influence society's view on environment. His research relates to how remote sensing satellites were developed in Sweden and Europe in late 20th century, how these were conceptualized and who had the power of defining the satellites' application.

Johan is also part of developing active student participation in Sweden, and have given several reports and keynotes on the topic. 


\title{
Tools for Transformation - How Engineering Education Benefits From Interactive E-Learning and the Humanities
}

\author{
By: Katarina Larsen and Johan Gärdebo \\ KTH - Royal Institute of Technology \\ Division of History of Science, Technology and Environment
}

This paper engages with how to construct tools for student activation, using analytical models, web-based feedback and critical reflectionin engineering education. Learning requires different levels of understanding and means to appropriate and formulate knowledge. However, peer instruction and student participation require a degree of facilitation, which is a role the teacher needs to analyse and develop before students can be demanded to demonstrate increased participation in course content, feedback and design. The specific context of student learning discussed here is based on experiences from a course for international engineering students at KTH Royal Institute of Technology, Sweden. The course aim is to train students in critically analyzing the role of national identities, social- and technological engineering and politics in shaping Swedish society. One challenge is to enable engineering students to develop skills in critical thinking by engaging with texts from social sciences and humanities dealing with topics formulated in the course aim. Reading, writing and discussing texts on historical and contemporary examples are used to attain learning outcomes, relating to both course content as well as practical skills of critical reflection, reasoning and developing arguments in writing. This study draws on experiences from changing a course previously relying on mandatory attendance towards challenging and encouraging the students' contribution to each other's learning. 


\section{Introduction: Tools For Transformation}

Imagine coming into a classroom, an auditorium housing 150 students. After setting up your computer and PowerPoint-presentation, the bustle quiets down and you begin by welcoming the crowd to your country and university. Though they come from all over the world,from different societies, cultures and schooling, thestudents have two things in common: all of them are engineering students, and; none of them have been to a seminar before.

For most students, the course Swedish Society, Culture and Industry in a Historical Perspective (SweSoc) is one of the first they attend at KTH and also serves as an invitation to understanding the society they now live and study in during their time as an exchange student. SweSoc was inspired by similar curriculum offered to exchange students at Massachusetts Institute of Technology (MIT) to better contextualize MIT and American society in the $20^{\text {th }}$ century. Furthermore, SweSocaims to introduce engineering students to analytical and critical thinking as used within the socialsciences and humanities[1].

This paper outlines the means by which engineering students at a technical university in Sweden are trained fordeveloping analytical and critical thinking, despite little or no experience in these subjects prior to taking the course. Furthermore, the number of students also poses a pedagogical challenge for how social sciences and humanities traditionally organize teaching activities with students. In order to introduce a large cohort of engineering students to these disciplines, we have conceptualized a set of models that we label as tools for transformation: analytical thinking, critical reflections, and web-based peer feedback of the student's work. We argue that these tools advance the student's analysis and enablesconstructive peer-comments. At a deeper level, these tools may transform engineering education towards made by future employers on skills necessary forteam communication, critical reflection in relation to sources and assumptions. 
From the perspective of pedagogy and classroom learning, the underlying reasons for implementing these tools are to:

- Advance the student's ability of self-assessment through explicitmodels and frameworks for analytical thinking, discussing and writing texts, within the humanities and social sciences.

- Practice peer learning through combining web forums and seminars.

- Reflect on learning process to achieve a meta-understanding, e.g.awareness of their learning process and ways to improve further.

The paper is organized in fivesections. The introduction outlines the aim of the study,the pedagogical learning perspective for methods introduced in the course and provides a background to the course developments in the context of social sciences and humanities in engineering education. This section also describes sources used. The second section describes how the course shifted fromdescriptiveto analytical and reciprocal learning.The third section accounts for theory and previous studies relevant to the analysis followed by a section for results and conclusions. The fifth section is a discussion of the implicationsfor engineering education.

\section{Social Sciences and the Humanities in Engineering Education}

Today's engineering students will be operating in a society full of 'wicked' problems. They are wicked because problems are not necessarily solved but changed since the subjects that a problem-solver is working with relate to humans. This requires the engineer to think analytically and critically, not only on technical issuesbut also on those that are social and humanistic[2, 3].KTH's examination criteria, in accordance with the Qualifications specified for Master of Science in Engineering in the Swedish Higher Education Ordinance[4], includes requirements onthe students to demonstrate the ability to identify, formulate and deal with complex issues, and to present his or her conclusions, and the knowledge and arguments on which they are based, in speech and writing to different audiences in both national and international contexts. Students are to demonstrate capacity for teamwork, ability to identify lacking analysis and critically but constructively pursue development of that analysis. The question that 
faced us was to design course content and activities that supported students in demonstrating the abovementioned skills.

In the course SweSoc, teachers' have made a tradition of beginning every semester with a poll among the students. The poll serves to identify the geographical and educational background of students attending the course.Most students have their background in city-planning, the second largest category is in information and communication technologies while the third and fourth are specialized in architecture and chemical engineering.In terms of geography, about half of the students are from the European Union, with North America and Asia being the second largest groups. South American and African students are few, between one to five out of 200students each semester since 2010 .

We also poll the students' assumptions of Sweden and the Swedes. Some themes are recurring: Sweden is a neutral welfare state, sustainable development is important and the population is culturally homogenous. However, as the course progresses this initial picture gives way to a more heterogeneous interpretation:Swedish history of the $20^{\text {th }}$ century does provide examples of segregation of migrants in urban areas, historical involvement in colonization and conflicts over natural resources in areas of the indigenous Sami population living in Sápmi and Scandinavia.In order for engineering students to understand these societal processes, this course was designed not only to review research and policy relevant for engineers but also to support analytical thinking and critical reflection asconceptualized within the social sciences and humanities

The teacher who initiated SweSoc in 2004,Arne Kaijser, had already in 1998 identified the need for critical analysis in engineering education. He based the argument for a reform of engineering education on changing demands in the skills of engineers, and pointed out some key problems:

The students are not encouraged to think critically or questioning. The education is based on duty and discipline rather than lust and curiosity. The student who wants to pass the exam better learn exactly what the teacher recommends, not more or less than that. One indirect consequence of the authoritarian form is that the engineering students are lulled into a false sense that most problems they will face in their future professional life have an exact solution: it is just a matter of finding the correct equation to apply[5]. 
To mend this situation,Kaijser's remedy was to supportengineering students in developing a dual competence, combining engineering with environmental studies, medicine, or a joint-engineering degree in language studies or the social sciences (including project-based studies). While these changes in content of education allow students to better grasp the connection between politics, large technological projects and societal effects, the issue remains how to pedagogically introduce students to assessing information and thinking analytically and critically. Thereby, one motivation of the study is to analyze and discuss the potential of tools that could achieve this in a practical way by introducing course activities of analytical thinking, critical reflections, and web-based peer feedback of the student's work.

Between SweSoc's initiation in 2004 and its present design in 2015, the course has undergone major changes. The student cohort grew from 25 to 200 students. Tasks shifted from individual to group assignments, from teacherto peer feedback, from activity at seminars to activity on web forums. These changes have resulted in examination shifting from students writing several, comparative, essays throughout the course towards taking one final, summative, multiple-choice examination at the end of the term[6-9]. Course analysisidentified the students' analytical skills to be deficientwhile measures taken sought primarily to address students' time-on-task through increased mandatory attendance and descriptive examinations of course content. However, the long-term solutions identified by the course coordinators were to develop routines for analytical thinking. Examples of this would be to hold seminars at the start of each semester focusing on analytical and critical thinking along with developing models for peer feedback to train the level of analysis. All efforts does require facilitation or support from teachers in order to shift from descriptive to more analytical education[10].

In the fall of 2014, the authors redesigned the course to shift from descriptive towards analytical learning. Bydescriptive we here refer to examination assessing skills where students account for and provide a summary of course content while analytical requires students to assess and critically reflect on the feasibility of arguments presented in the course literature. In order to introduce students to these forms of learning we used explicit models on analytical thinking, with course content 
structured around analytical questions andwithrequirements for peer learning throughfeedback in seminars and web forums.

Course content was organized as learning outcomes that were to be addressed through analytical questions. These questions were assigned specific lectures, excursions, films and course literature, although students were encouraged to explore any overlaps and further literature they found relevant for answering the analytical questions. As examination was based on the components of the analytical questions, students were encouraged to engage with the course content to answer the questions analytically and critically rather than memorize all descriptive content of the course.

\begin{tabular}{|c|c|}
\hline Learning Outcomes & Analytical Questions \\
\hline \multirow{3}{*}{$\begin{array}{l}\text { The main purpose of the course is for students to } \\
\text { anlayse how changing cultures, ideologies and } \\
\text { political ideas have shaped and re-shaped Swedish } \\
\text { city planning, technology and industry in the post- } \\
\text { WWII period. }\end{array}$} & $\begin{array}{l}\text { "What makes a national myth? Are these persistent or } \\
\text { replaceable?" }\end{array}$ \\
\hline & $\begin{array}{l}\text { "How has the emergence and disappearance of the } \\
\text { successive City Building Regimes (CBR) in Post-War } \\
\text { Stockholm influenced the city's development?" }\end{array}$ \\
\hline & $\begin{array}{l}\text { "How does a system approach to a resource compare to } \\
\text { one that regards the resource as a "commons"?" }\end{array}$ \\
\hline \multirow{2}{*}{$\begin{array}{l}\text { After the course, the students should be able to: } \\
\text { - Outline and explain the main characteristics } \\
\text { of the "Swedish model" (political system, } \\
\text { welfare state and neutrality/non-alignment). } \\
\text { - Outline and explain the general development } \\
\text { of Swedish industry and technology in the } \\
\text { post-WWII period }\end{array}$} & $\begin{array}{l}\text { "Do you consider the development and changes in the } \\
\text { Swedish welfare state over time to be more a } \\
\text { consequence of domestic factors or of external factors? } \\
\text { Support your answer with arguments from course } \\
\text { readings and the lecture." }\end{array}$ \\
\hline & $\begin{array}{l}\text { "What are the main explanations for the growth and } \\
\text { decline of different forms of natural resource } \\
\text { exploitation in the Arctic region from the } 17^{\text {th }} \text { century } \\
\text { until present? Motivate your answer in relation to the } \\
\text { readings and lecture!" }\end{array}$ \\
\hline \multirow{2}{*}{$\begin{array}{l}\text { - Outline and explain the basic characteristics } \\
\text { of Swedish city planning during the post- } \\
\text { WWII period. }\end{array}$} & $\begin{array}{l}\text { What types of governance arrangements would you } \\
\text { consider optimal for implementing a climate change } \\
\text { adaptation strategy in Sweden? Top-down actions, } \\
\text { bottom-up actions or a mixture of both?" }\end{array}$ \\
\hline & $\begin{array}{l}\text { "Reflect upon the lecture and course reading and } \\
\text { motivate which school you think best describes Swedish } \\
\text { security policy during the Cold War?" }\end{array}$ \\
\hline
\end{tabular}

Figure 1.Learning outcomes and analytical questions of SweSoc Fall 2014

The term analytical thinking refers here to distinguishing between elements of thought, overviewing several perspectives and large sets of information, exposing source bias, and to synthesize these in a fairly short amount of time. The term 'Critical reflection' refers here to the student's questioning, self-reflective, approach to what is read, written, spoken or heard. Critical reflections presuppose analytical thinking. Indeed, students could approach an argument analytically but not critically if the point is to understand the argument rather thanto deconstruct its content, which would be achieved in the next instance using a critical approach[11]. Critical thinking 
is described either as a 'graduate outcome', a generic skill acquired by the student throughout higher education, or as a trait embedded within the discipline taught. In both these cases, critical thinking is not a personality development of the student but a development of skills that the university isresponsible for supporting[12].

For this reason, critical thinking has been combined with standardization of assessment criteria and increased focus on depth of student work[13]. While analytical questions were subject specific for our course, the models with which the students worked were described as general tools for organizing thought and made as explicit as possible.

\section{Gathering Data and Source Material}

The primary material consists of course evaluations and feedback from students at lectures and seminars. We are interested in the students' metacognition, their thinking about thinking, and how the course may have influenced this.

Students used web-forums to give peer-feedback on each other's seminar essays. Our analysis used this feedback to assess how the students had learned to work with explicit modelsfor analytical thinking and critical reflection. For this purpose, the comments from the web-forums were categorized and analyzed in relation to how the student performed on the course (final grade). The texts commented on in the webforums represent an earlier (and shorter) form of essay and are a mandatory assignment of the course. While essaywriting was not mandatory for passing the course, they were required in order for students to achieve higher grades on the final examination.

Hence, the results presented here draw on students'comments and the categories of analytical and critical learning categories they represent (not the written text themselves) as the primary source material usedto discuss the students' selfassessment and learning process.Additional sources include historical material of the course for comparison of course objectives, methods for achieving these and more general changes and challenges the course has faced. 


\section{Shifting from Descriptive to Analytical and Reciprocal Learning}

For SweSoc, fall 2014, we used pedagogical tools that could introduce our engineering students to analytical thinking and critical reflection while also getting them started with the course content to begin with. The models were explicit, question-driven and adapted to facilitate larger groups of up to 200 students. These changes to the course, we argue, have the potential of shifting learning outcomes from descriptive to analytical and reciprocal learning.

In terms of learning outcomes, students were to demonstrate an ability to write a critical analysis of a chosen topic in an essay drawing on course literature and discussions from seminars and other course activities. The activities were designed to:

- Stimulate seminar groups to discuss course content in order to practice deconstructingtexts, get the students familiar with the course readings early on in the course.

- Practice constructive comments and feedback on other students' texts and incorporate comments received into arguments in the course essay.

\section{Pedagogy for Analytical Thinking and Critical Reflections}

Students were to use models to answer analytical questions, which required reading and breaking down the content of texts, lectures and excursions as well as writing up and answering analytical questions in relation to seminars. The analytical questions required students to use the explicit models for analytical thinking (Figure 2) and critical reflection (Figure 3). In thismethod, the teacher and peers expose the student to question-based learning, which derives from 'Socratic' dialogue where the student's thinking develops through increasing degrees of analytical questioning[14]. The teacher supports the students in outlining the 'Elements of Thought', where thinking is assumed to consist of eight analytical elements:

Whenever we think, we think for a purpose within a point of view based on assumptions leading to implications and consequences. We use concepts, ideas and theories to interpret data, facts, and experiences in order to answer questions, solve problems, and resolve issues. Thinking, then: generates purposes; raises questions; uses information; utilizes concepts; makes inferences; makes assumptions; generates implications; embodies a point of view[15]. 
We are aware that the rigor of elements of analysis may impinge on other forms of discussion but chose the model since itoutlines analytical thinking explicitly and supports engineering students,as an introduction, to reading and writing analytically.

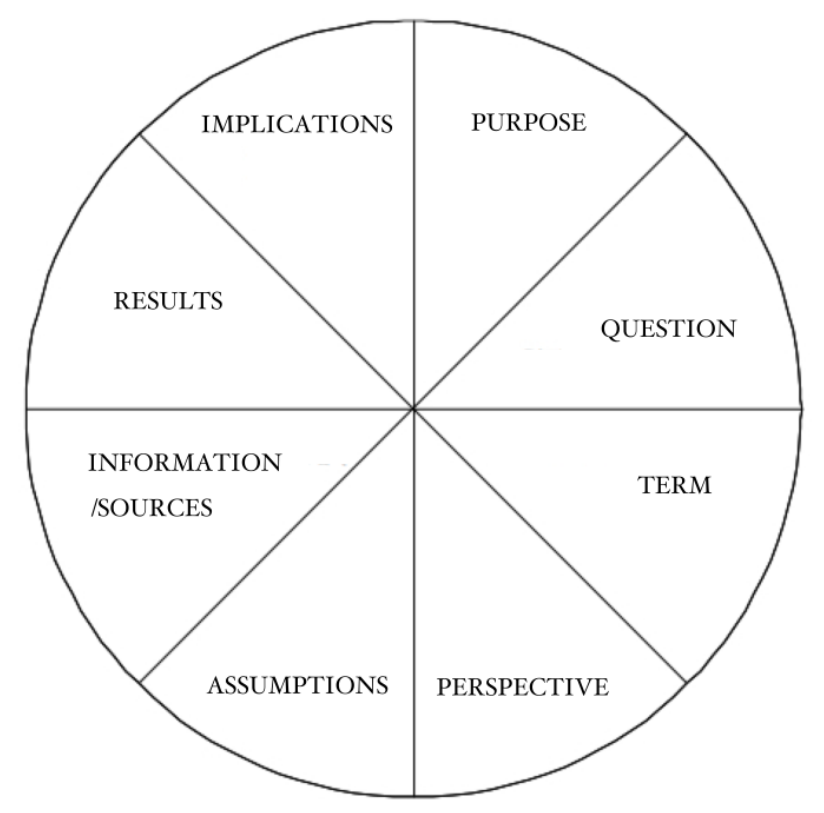

Figure2: Elements of Analysis[16]

Each text was broken down into its elements to support comparison between them and other texts. This process could be taken further with students evaluating the elements according to intellectual standards, e.g. if the text's results are relevant to the student's questions, if it is precise or clear, to mention a few[16, 17]. While these approaches are recommended in other studies using elements of analysis, our aim with SweSoc was not to reach depth of argument but a broadening of the engineering students'set of skill, assuming that a proper introduction to analytical thinking would serve as foundation for further development and understanding of social sciences and humanities later on. Similarly, our aim was not to cultivate profound understanding of all problems facing Sweden, but to enable the students to problematize general accounts and narratives of society.

To support the introduction of analytical thinking and critical reflections, the evaluation of elements of analysis was standardized as a set of questions. A checklist was also used to guide students in arguing for what theypersonallythought of a text by critically reflecting on results presented in relation to methods, empirical design, novelty, and writing style, see Figure 3 below. 


\begin{tabular}{|l|l|}
\hline $\begin{array}{l}\text { METHOD: } \\
\text { Strength/weakness of approach used? }\end{array}$ & $\begin{array}{l}\text { NOVELTY: } \\
\text { Why is the text interesting and novel? }\end{array}$ \\
\hline $\begin{array}{l}\text { EMPIRICAL DESIGN: } \\
\text { Alternative ways to carry out study? }\end{array}$ & $\begin{array}{l}\text { WRITING STYLE: } \\
\text { Alternative ways to write the paper? }\end{array}$ \\
\hline
\end{tabular}

Figure 3.Critical reflection on results in texts[18]

In addition to the tools for analytical thinking and critical reflection, we provided the students with a model for clarifying expectations on responsibility as relating tohow analytical questions were to be answered (Figure 4). The outline served to support student understanding of how analytical questions connected to course content and specific lectures, excursions and seminars.

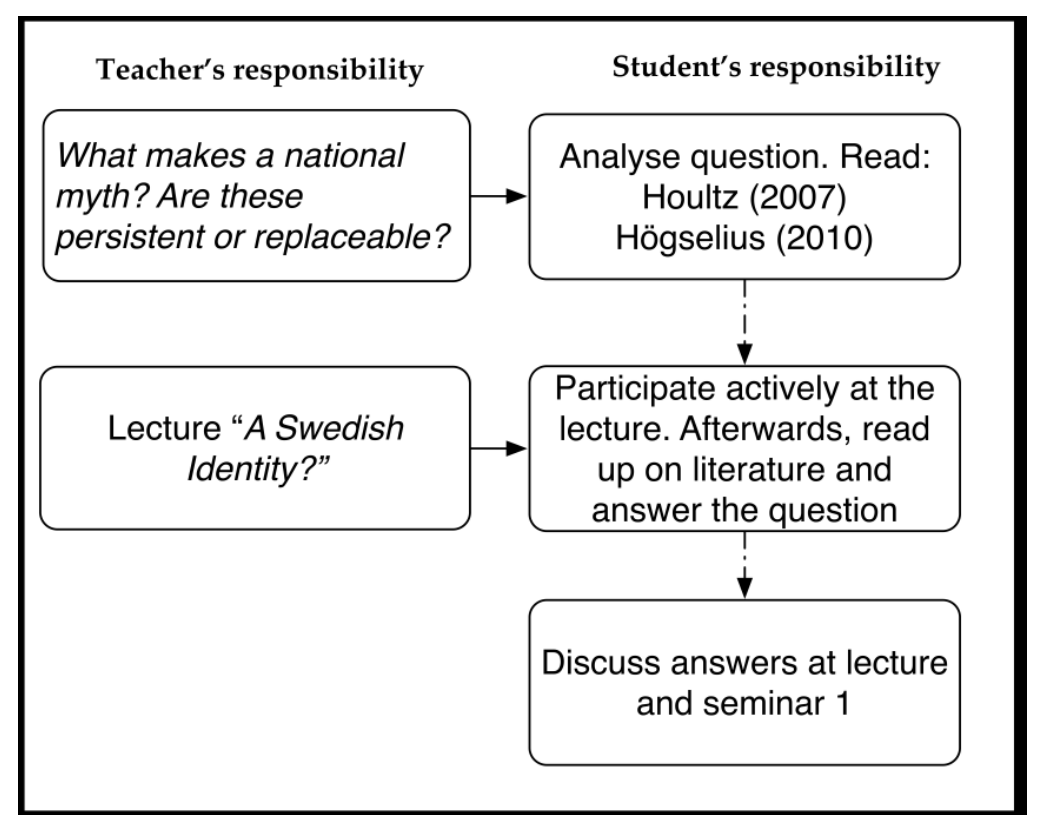

Figure 4: Responsibility for course content as divided between teachers and students[17] Note: cf. C. Lagerqvist (2010) where feedback is given in tutorials consisting of one teacher and oneto-four students.

In order to work with the analytical question, we provided a model for time allocation (Figure 5) in academic reading and writing as conducted through three separate sessions. Session 1 is brief but serves as an overview of the content and ends with the studentsraising a tentative answer to the analytical question. Session2 is where the students use elements of analysis (Figure 2) to break down the text into eight elements or components. Finally, in Session3 the students return to their tentative answers, nuancing them by writing a 1-page summary of the text based on the notes from Session 2 butreformulates these using their own language and reflections. 


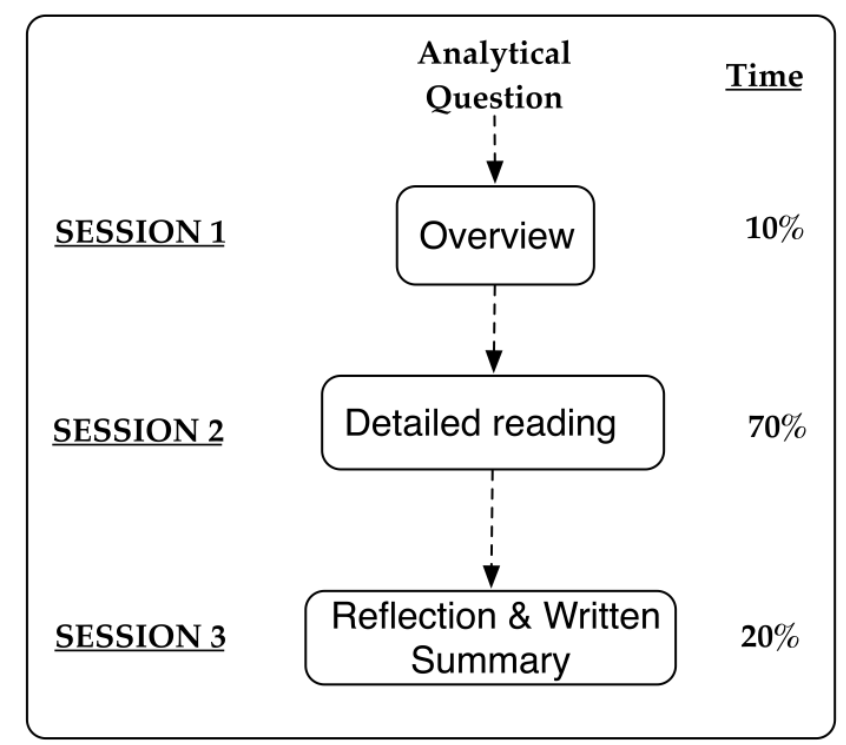

Figure 5: How To Read An Academic Paper - Session 1, 2 and 3[19]

Upon finishing Session3, the student has both amassed analytical thinking about the text and a critical reflection of its role in answering the analytical question for the lecture, seminar and eventually the examination of the course.The examination was based on the analytical questions that students had been working on throughout the course, either as sub-sections of the analytical questions or as part of the written course essay.

\section{Theory and Previous studies}

\section{Self-assessment, Peer-Learning, and Feedback}

Students, who have never attended a seminar, ask themselves: "How can I best write a text, which presents the argument I want to make in the text I am writing for this seminar?" In seeking to answer this questions, ourstudy is similar to studies on reciprocal questioning[20]and seminars where teachers guide the students' selfassessment and monitoring process[21] but in addition we are concerned with achieving this through peer learning and feedback. Course activities of a formative character, such as practicing analytical writing and developing arguments in course essays, raise questions about how feed-back is best used in instruction to students. How can students be supported to use self-assessment in academic writing as an integrated learning process? 
The other aspect is if the student has reached a level sufficient to the criteria used for assessing course essays. The students practiced this by working with analytical questions, through individual and peer learning with feedback given in seminars and web forums. All analytical questions required students to give constructive comments to texts.

Studies on feedback emphasizethe development of self-assessment skills through using peer support groups while practicing feedback[22]. The seminar activities of the course are considered as forums for constructive feedback to the student's learning process. Hattie and Timperley (2007) conceptualize feedback as: “information provided by an agent [e.g., teacher, peer, book, parent, self, experience] regarding aspects of one's performance or understanding." But what does it mean in practice? Feedback would serve its purpose best if given in relation to a task it improves upon [23]. This could for example be the writing, reading and commenting of texts that emulate a similar essay for the students' examination. Another important aspect of feedback that warrants further attention is to understand how it is most useful to students and how students make sense of and understand feedback.However, pedagogical studies about feedback have not focused on how students make sense of feedback (only 4\% of studies reviewed in Evans 2013) compared to topics such as elearning $(22 \%)$ and more general themes such as peer-feedback (17\%). The same review points to another understudied area, namely the motivation of feedback on learning where only $2 \%$ of studies in review focused on reflection and personal motivation in engineering education.

Motivation is warranted as engineering education increasingly preparesstudentsto becomefuture project members in multi-disciplinary teams. Skills for understanding different disciplinary motivations for learning and solving wicked or complex problems, requires critical reflection, analytical thinking and ability to enable crossteam learning when interpreting a problem.A contemporary example ofthis is a model for communication across teams in the software companySpotify, drawing on competences from members with diverse educational backgrounds[24], The fluid structure of these teams requires substantial flexibility while engineering education traditionally is associated with formal structures for supporting student learning, trough use of learning outcomes and instruction [25]. 


\section{Vygotsky's Zone of Proximal Development}

Educational tools need to be adapted to the area where learning takes place and with a sense of how learning occurs. Lev S. Vygotsky'ssocial-historical theory of cognitive development argues that tools are central for shaping the skills a human acquires. $\mathrm{He}$ derived the concept of 'tool' from Friedrich Engels' work on how material tools developed speech. Vygotsky expanded the definition of tools to include psychological concepts as enablers of more abstract thinking. Through tool instruction, students were able to develop models of thinking, writing and speaking [26, 27]that over time supports their metacognition, i.e. thinking about thinking. This is characteristic of self-assessment and central to achieving the course objective of analytical thinking.

For these reasons, SweSoc was designed to emulate what Vygotsky labeled as the student's zone of proximal development(ZPD) for learning new skills. The zone contains functions that are within the student's reach toperform today, with assistance, but will manage alone tomorrow[28]. 'Instruction' is to be a scaffold to support thestudents' exploration of their zone of proximal development. Instruction is then gradually removed and shifted towards more challenging tasks which are now becoming available to the student.

\section{Learning Together-Active Student Participation}

Vygotsky treated learning as a cultural development, first occurring on the social plain and later on the psychological. Systems of speech, writing and numbering are first practiced out loud before becoming internalized[28].

We sought to make systems and models for learning explicit, outlining how we defined 'analytical thinking' and what was expected of students for making their reflections 'critical'. These models were practiced in seminar groups and later individually or on web forums. Additionally, several forms of education activities were combined to support different types of social learning.The students made excursions to suburbs when readingabout city-planning. Lecturers ended their presentations by screening popular Swedish movies that connected to the course content of identity and culture. When students answered analytical questions about Swedish society we asked them to discuss and connect these topics to their own 
countries and background. The aim was to facilitate explicit but different forms of learning to activate individual and reciprocal learning and participation among the students.

Active student participation has been described as a means for improving learning and engagement of students, in time reforming education and the curriculum[29]. Broadly defined, active student participation refers to students taking an active role in each other's learning, as mentors, amanuenses or extra teachers. And it is by university efforts of facilitating a structure for co-ordination participation that efforts can endure $[30,31]$.

Several frameworks for collaboration have been outlined and means for implementation proposed[32] as well as means to improve digital literacy among humanities students[33].

However, student participation usually requires a community, with necessary elements being membership, influence, reinforcement and shared emotional connection[32] of which all werelacking in this course. SweSoc membership is limited to between $20-25 \%$ of the student'sworkload, for some it is not evena compulsory course; student-influence is impinged by that their exchange lasts only six months and with having few means to revise the course design within this timeframe; the course served student needs of integrating and understanding Swedish society, but benefits for their engineering degree usually became apparent only later in the course, and; although course activities were varied they did not always have direct importance for examination $[34,35]$.

Since community is crucial to student participation, the conditions mentioned above present any project of redesign in courses like SweSoc with severalchallenges. Being aware of this difficulty, we sought to introduce analytical and critical thinking through including them in all models, alternative activities and web tools throughout the course, returning to the importance of self-assessment in various arenas.In the context of the course SweSoc, this requires teachers to support students in developing their ability to reflect, compare, contrast and theorize. The necessary skills for this is to support the students in reading, writing and reflecting on texts from social sciences and humanities in seminars, the written course assignments and eventually in the final 
course essay. The students are required to demonstrate learning outcomes by working with and discussing key concepts and implications of an argument put forward in a text. This is different from summarizing and accounting for content provided in a text.

The pedagogical focus on what the students are expected to learn during courses raises questions about different types of knowledge and if there are certain skills needed in order attain certain types (or levels) of knowledge in relation to learning outcomes and course content. The model SOLO (structure of learning outcomes) discusses phases and levels of understanding in terms of quantitative phase (where students identify and do simple procedures) and qualitative phase with an analytical focus where students compare/contrast, theorize, generalize, hypothesize and reflect[36].

We argue that it is valuable for engineering students to demonstrate analytical thinking and critical reflection. And it is of relevance for engineering education as a whole in order to address complex problems (interdisciplinary solutions to grand challenges in climate change, demography etc.). In this context, the role of affect in education is relevant, but as noted by Evans (2013) also an understudied areas for analysis in studies of feed-back. In a study of syllabus, developed by the CDIO consortium (Conceiving, Designing, Implementing, and Operating), the model for critical thinking, presented in Figure 2, is analyzed and adapted to the challenge of engineeringeducation. The model is briefly described and exemplified by questions asked by engineers also outlining Engineering affective dimensions, including examples such as "exercising independent thought and judgment" and "recognizing different stakeholder point of view" in addition to cognitive dimensions (Engineering macro-abilities) such as "selecting critical questions to be answered" and "evaluating technical arguments"[37].

In the context of the course SweSoc, these ambitions for critical thinking in engineering education requires teachers to support students in developing their ability to reflect, compare, contrast and theorize. The necessary skills for this is to support the students in reading, writing and reflecting on texts from social sciences and humanities in seminars, the written course assignments and eventually in the final course essay. The students are required to work with tasks relating to learning outcomes that demonstrates knowledge by outlining key concepts and discuss 
implications of an argument put forward in a text (rather than summary of texts and a single focus on accounting for facts provided in a text).

\section{Results and Discussion}

The results of the study focus on students' analytical skills and peer feedback responding to how to:

- Advance the students' ability of self-assessment

- Practice peer learning through combining web forums and seminars.

- Reflect on learning process to createawareness of their learning process and ways to improve further.

Since 2010, course coordinators had reported difficulties in instructing students to read and write analytically.Apart from the challenge of introducing students to analytical thinking and critical reflection there was a need to make them accustomed to working with the course material early on. Many students postponed substantial reading until the mid-semester seminar,with understanding of the course content subsequently being at low levels and made peer commenting superficial. In response to these difficulties, course coordinators made examinations and peertasks more descriptive, with mandatory attendanceadded as requirement to pass the course.

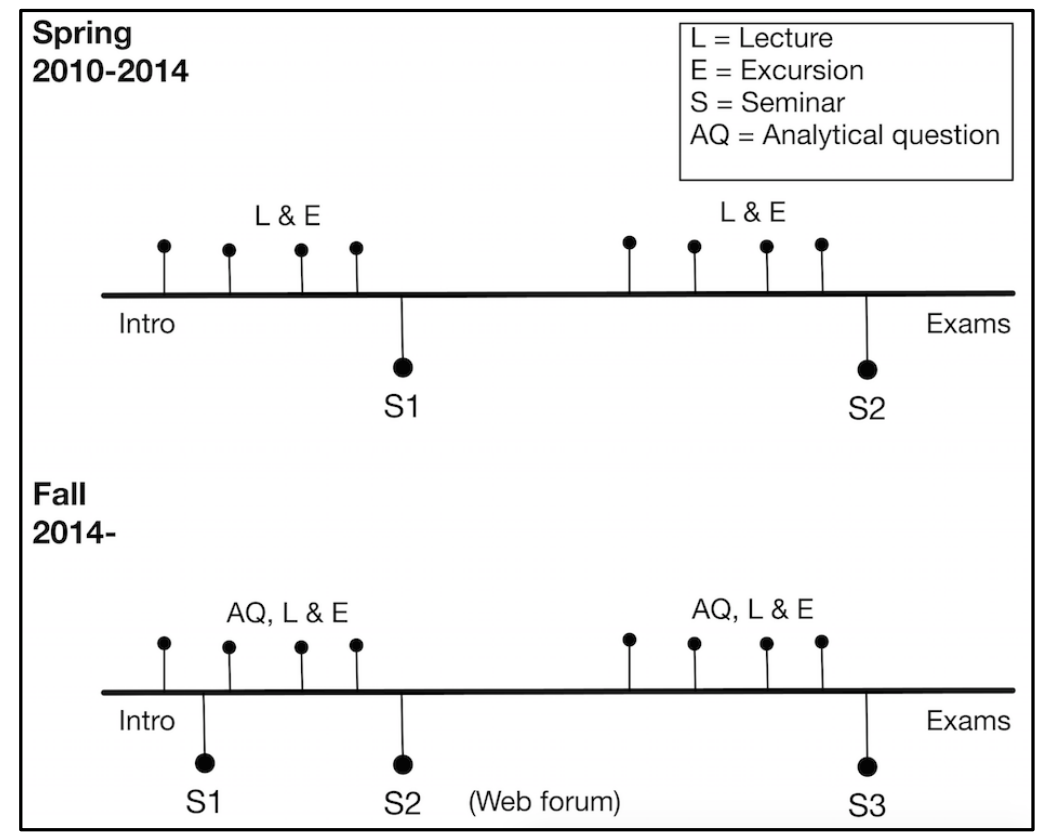

Figure 6: The SweSoc Semester 2010-2014 and redesign in fall 2014. 
In fall 2014, the teachers ofSweSocprovided previously mentioned models on thinking (Figure $2 \& 3$ ), reading and writing (Figure $4 \& 5$ ) during the first week of the course and connected these directly to analytical questions, lectures, excursions and texts. By mid-semester, the students had already worked with the course material in several ways. Students had discussed with each other at seminars. They had written and commented texts on web forums and at seminars. And they engaged with the course material throughanalytical questions in connection to lectures and excursions on the same topic (Figure 6). Additionally, mandatory attendance was downsized with the possibility of doing make-up assignments that focused on the analytical questions.Through these changes, we sought to support the students in developing self-assessment and peer feedback and thereby achieve the SweSoclearning outcomes.The theoretical perspective of zone of proximal development discussed by Vygotsky describes this in terms of functions that are within the student's reach to perform today, with assistance, but will manage alone tomorrow.

\section{Peer Feedback}

By mid-semester, we assessed how student self-assessment, peer learning and web forums had functioned as tools for transformation. Student feedback was used as an indicator of the degree to which studentshad operationalized tools for analytical and critical thinking in the course so far.

Feedback was given by peers in the shape of fellow classmates, who had all been given the same instructions regarding how to deconstruct texts, elements of analysis, frameworks for advancing an arguments in a short text (500 words) in preparing for seminar activities, and academic writing for developing a longer text (1000 words) in the final course essay.

For the seminars, students wrote texts aimed at answering an analytical question, and similarly they had to comment on texts of other students. The explicit models for analytical thinking and critical reflection (Figure $2 \& 3$ )were also used to analyse peer comments and the degree to which students demonstrated their skill and proficiency of the models. 
Feedback has here been summarized using categories from 'Elements of Analysis' and 'Critical reflections', both of which illustrate how students have organized their thoughts. Our analysis concerns the student feedback and peer-comments, and not the texts themselves. Figure 6 shows how frequently different categories are included in student peer-feedback in the web-forum including categories concerned with components of texts (key terms etc) but also and comments on analytical categories such as argumentation, implications and alternative perspectives.

Students demonstrated ability to use the terminology of analytical thinking and critical reflections for explicit aspects of the text, such as the use of key terms discussed by 69 percent of peer-comments, perspectives (70 percent) and results (73 percent). However, implicit aspects such as an author's assumption (6 percent), the purpose (17 percent) and implication (25 percent) of arguments were less often elaborated in feedback. Feedback was mostly constructive (91 percent), and many exemplified these comments (62 percent). Apart of the analytical comments, much emphasis was put on how to improve the formal aspects, ( 89 percent) e.g. text structure.

The model Elements of Analysis is used to make explicit the logic of a text, and as such it the model is best suited for working with elements that are explicit themselves. More extensive studies in background and perspectives would have yielded insights into what assumptions there are in our field of humanities and social Sciences, and consequently also what implications follow from different arguments.

One interpretation of low attention to the categories such as purpose (17\%) is that the purpose was, already at the outset, explained by the writing assignment. However, our understanding is that students, who did reflect on the purpose of the text, did so by applying a higher level of analysis not taking the given question for granted. Rather, there are some examples where students have written peer-commentsacknowledging that a fellow student challenged the questions in the assignment in the web-based forum. 


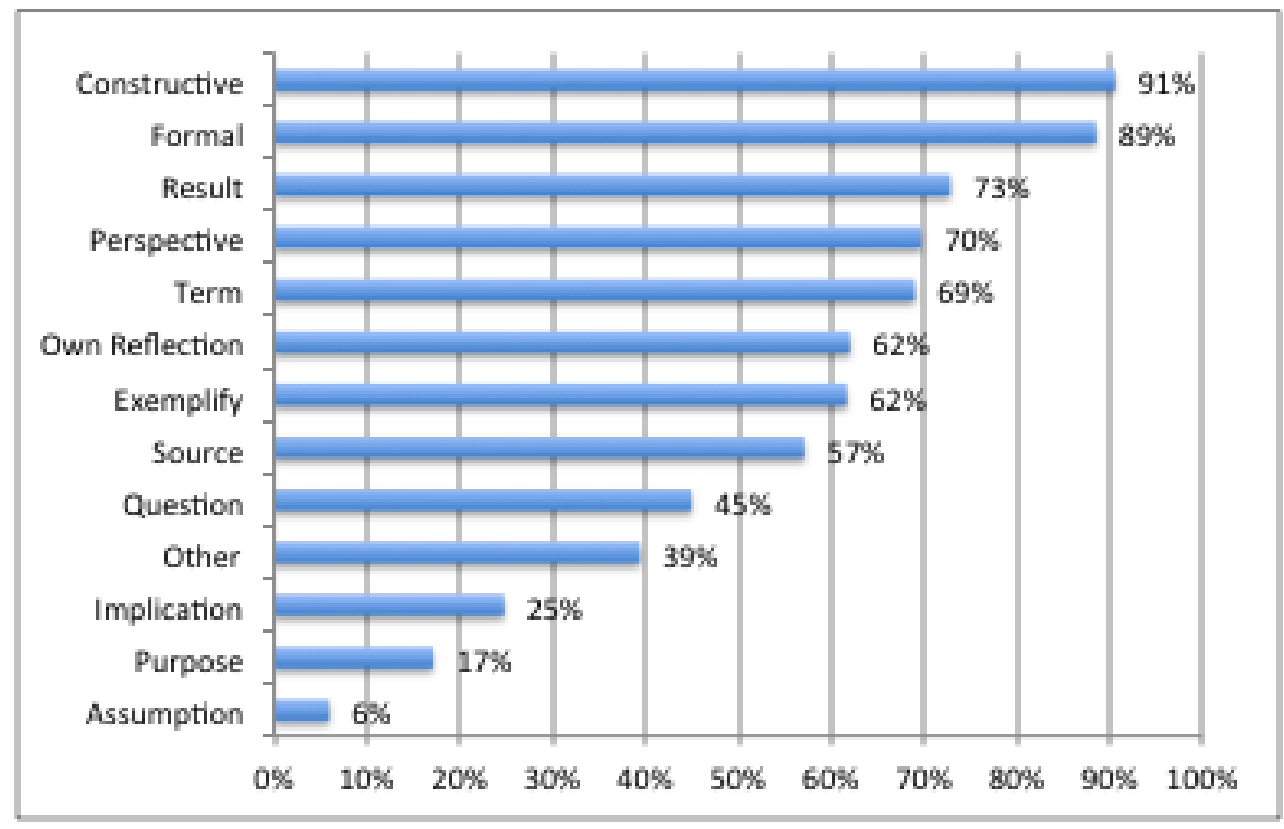

Figure 6.Categories for feedback in second seminar when students are giving peerfeedback in course web forum (percentage of students who used each category for feedback).

This type of analysis, about how students focus on certain aspects of elements of analysis in peer-comments, is one type of information such forum can provide to teachers in engineering education. Thereby getting a better understanding of how students worked with analytical and critical perspectives when giving comments on a classmate's text. The written reflections by students in the web-forum can also be used understanding of students' reflections in relation to learning processes and their thought process about what they could improve with their own writing in the same exercise and for the final course essay. Thirdly, an on a more future oriented note, the peer-comments in the forum can also be valuable to better understand how students who provide peer-comments in certain categories (which requires analytical and critical thinking) do perform in terms of final grades. For example, the category of "Implications" (see figure 6) was used by one forth of the students. In this group of students about $32 \%$ received the grade $\mathrm{C}$ or higher, compared to about $27 \%$ of students in the whole class. Although interpretation of these results should be made with caution, the analysis of sub-categories provides some interesting points valuable for discussion about learning processes and use of web-forums for feed-back and reciprocal learning. Furthermore, a detailed analysis of these students' essays would be of interest to understand whether in their final essay they included an analytical 
perspective on implications and own reflections when applying models from the course to write their essay for the examination.

We need to stress here that in while shifting emphasis to explicit models for analytical and critical thinking, with support of peer feedback and web forums, by no means decrease the workload involved on part of the teacher. But redesigning curriculum should not require substantially more resources since it then becomes difficult to improve course design and seminars. Rather we sought to do SweSoc differently, shifting the teacher role towards that of a facilitator, giving instructions to the models of learning while administrating the tools for transformation as it were in order for the students to optimally use these for their own learning. The students' role have shifted from time-on-task participants towards managers of their time in adequate amounts as described through the explicit models for distributing their work effort in order to answer questions analytically and critically. Furthermore, we argue that one result of peer feedback is its support in developing skills of dialogue and collaboration that a teacher-student interaction would have difficulty in achieving. 
Table 1: Categorization of peer comments given through the web-based forum for Swedish Society fall 2014

\begin{tabular}{|c|c|c|}
\hline $\begin{array}{l}\text { Category of } \\
\text { skill }\end{array}$ & Assessment/Definition of skill & Example of student demonstration of skill \\
\hline Purpose & $\begin{array}{l}\text { Does the essay answer the Analytical question (AQ) and/or } \\
\text { develops analysis rather than summarizing course readings? }\end{array}$ & $\begin{array}{l}\text { "There should have been a little stress that how these regimes influence Stockholm. I know it's } \\
\text { evident from what you have mentioned but I was expecting that you explicitly highlight it out a } \\
\text { little since that was the analytical question we had been asked." }\end{array}$ \\
\hline Question & $\begin{array}{l}\text { How has the AQ been pursued, e.g. in sub-sections, and has it been } \\
\text { motivated and answered satisfactorily? }\end{array}$ & $\begin{array}{l}\text { "Another thing that you might improve on is to motivate the question that you are trying to } \\
\text { answer and give some context before jumping right to the conclusion." }\end{array}$ \\
\hline Term & $\begin{array}{l}\text { How are terms defined and commented? How are the terms related } \\
\text { to the goal of answering the AQ? }\end{array}$ & $\begin{array}{l}\text { "Moreover, the clearly stated definition of a CBR (City Building Regime) makes the whole text } \\
\text { more understandable, not everybody did it and it is really nice." }\end{array}$ \\
\hline Perspective & $\begin{array}{l}\text { How is the background and context of the topic and AQ discussed? } \\
\text { What alternative perspectives are raised? }\end{array}$ & $\begin{array}{l}\text { "Through this text, you cover the economic aspect of Sweden from different points of view, } \\
\text { which is important in order not to stay on one influenced idea" }\end{array}$ \\
\hline $\begin{array}{l}\text { Assumption } \\
\text { s }\end{array}$ & $\begin{array}{l}\text { What assumptions does the essay have? How does the essay discuss } \\
\text { premises and unstated beliefs of the texts used for answering the } \\
\text { AQ? }\end{array}$ & $\begin{array}{l}\text { "I am a little bit confused when you raise the [issue of] identity. I can't find the strong } \\
\text { relationship among identity, immigrants and the development and changes of welfare state; } \\
\text { therefore, if you can explain how those subjects are related, it will help readers to understand the } \\
\text { part more." }\end{array}$ \\
\hline Source & $\begin{array}{l}\text { What references are used and discussed? How are sources and } \\
\text { source bias discussed and which alternative sources are suggested } \\
\text { (overlap with the category "other")? }\end{array}$ & $\begin{array}{l}\text { "A third point, which would improve your essay, would be the use of secondary references. } \\
\text { These could be from other papers, but also from what you learned during the course. This makes } \\
\text { your essay more colourful and actually also more valuable to read." }\end{array}$ \\
\hline Results & $\begin{array}{l}\text { How are inferences discussed, the main argument and its } \\
\text { plausibility? What in the conclusion is emphasized (overlap with } \\
\text { category "implication")? }\end{array}$ & $\begin{array}{l}\text { "Your essay is very critical and brings up a lot of arguments and counter arguments which is } \\
\text { really good. The way you give arguments criticizing the consequences of the regimes or that you } \\
\text { give a counter argument to each arguments." }\end{array}$ \\
\hline Implication & $\begin{array}{l}\text { How are consequences of the conclusion discussed? What follows } \\
\text { from the argument, both explicit and implicit? }\end{array}$ & $\begin{array}{l}\text { "Lastly there should have been a little stress that how these regimes influence Stockholm. I know } \\
\text { it's evident from what you have mentioned but I was expecting that you explicitly highlight it out } \\
\text { a little since that was the analytical question we had been asked." }\end{array}$ \\
\hline $\begin{array}{l}\text { Own } \\
\text { reflection }\end{array}$ & $\begin{array}{l}\text { Did the essay include any own reflections? To what extent are these } \\
\text { critical? }\end{array}$ & $\begin{array}{l}\text { "No personal reflections were made and therefore, I could not see what you actually felt about } \\
\text { the literature." }\end{array}$ \\
\hline Other & $\begin{array}{l}\text { How is other course content than texts used to answer the AQ, e.g. } \\
\text { lectures, excursions, seminars? What comparisons with other } \\
\text { countries, sometimes based on personal knowledge, are discussed? }\end{array}$ & $\begin{array}{l}\text { "One thing I could suggest is to extend the example to real experience like comparing the } \\
\text { different housing development between the place you live in Stockholm and the city you come } \\
\text { from." }\end{array}$ \\
\hline Formal & $\begin{array}{l}\text { How are improvements on the text structure, typos and grammar } \\
\text { commented? }\end{array}$ & $\begin{array}{l}\text { "Furthermore [you] should definitely back up more of your statements you make. There are no } \\
\text { resources listed, where you obtained your information from and not even the one you[r] writing } \\
\text { your essay about to begin with." }\end{array}$ \\
\hline $\begin{array}{l}\text { Constructiv } \\
\text { e }\end{array}$ & $\begin{array}{l}\text { Are comments described pedagogically and suggestions for } \\
\text { improvement offered? Is the language tone positive? }\end{array}$ & $\begin{array}{l}\text { "In terms of content, you summed up the content of the original essay very well. Still it lacks a } \\
\text { little bit of originality since you didn't add any of your own thoughts or ideas. Maybe you could } \\
\text { think about some with reference to the final essay." }\end{array}$ \\
\hline Exemplify & $\begin{array}{l}\text { To what degree does the commentator explain the constructive } \\
\text { suggestions, e.g. exemplify or paraphrase suggestions (this is a sub- } \\
\text { category of "Constructive" to distinguish the degree to which } \\
\text { comments for improvement were specific)? }\end{array}$ & $\begin{array}{l}\text { "Your final paragraph about the City Building regime frustrating citizens is a good example of } \\
\text { injecting a personal voice, but it would have been more of a joy to read your essay if you had } \\
\text { more. Perhaps you could have also added your opinions on our excursions to HammarbySjöstad } \\
\text { and Husby and linked them to one or several regimes you mentioned in the article." }\end{array}$ \\
\hline
\end{tabular}


In relation to literature on feedback, there are several mechanisms in our study that makes it probable forconstructive feedback to occur. Firstly, students who produce text are those who will have their texts commented, hence the prospect and promise of personal feedback, for which the student becomes personally responsible. The second is the discussion following on this task amongst peers, which they were more likely to engage in empathetically having already written a text of their own. Hypothetically it could have been their text that was discussed at the seminar. Students were required to provide written feedback as it was meant to serve as preparation forthe final course essay. At the end of seminar 2, we asked the students to fill out a survey on how much time they devoted to this particular seminar assignment, i.e. student time on task.A total of 150 replies were collected. Results are shown in figure 7 below:

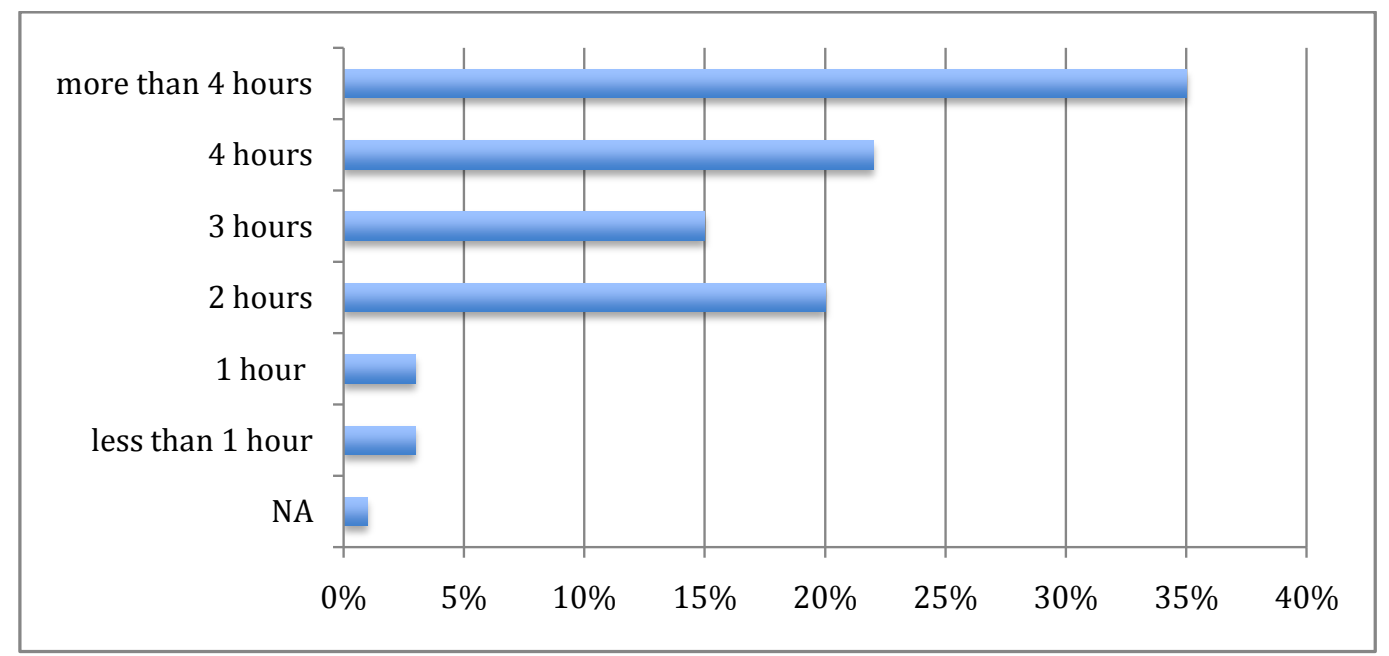

Figure 7. Student time on task in preparation for the seminar 2 assignment (percentage of student replies). Students replied how much time was spent on the writing assignment for seminar 2.

The students were also asked to answer when they started working with the assignment (days before deadline). This information was collected to learn more about when the students got started with preparations, i. e. if the assignment triggered activities outside the classroom in preparing for the seminar activity. The answers can also give an indication of if students started to read early on in the course or only read prior to the exam. The survey showed that students, on average, started reading 3-4 days before deadline while $12 \%$ of students had begun more than seven days prior to deadline. 
To conclude, more than one third of the students (35\%) used more than four hours to prepare for this task, including reading and writing. In a sense this, is a way to create a learning environment and forum for peer-comments early in the course so students should read texts actively in relation to the analytical questions provided.

Hattie and Timperley do mention students giving feedback, but emphasis on benefits is how the student receives. In contrast, we argue thatgiving feedback is central to thinking analytically about writing, both ones own and that of others. Giving, rather than receiving, feedback is also to be contrasted with the tutorial model in which a researcher gives personal feedback to written essays on a weekly basis[17].Active student participation in feedback was made available through web-forums. The linkage between students giving feedback and developing analytical skills was explicitly stressed by teachers..

What we would argue here is that student activation and learning occur whenquestions are asked. The classroom, web forums and intellectual content have in this course all been organized towards questions, and what students have learned is to formulate questions. In this sense, 'feedback' between students is not secondary to learning, but another aspect of asking questions.

\section{Conclusions and Implications for Transforming Engineering}

\section{Education}

Engineering education is shifting in response to demands from an increasingly complex society. In order for university's to support students in critical thinking, we have in this paper argued for a set of tools that shift emphasis from descriptive to analytical learning and which relies on reciprocal learning for transforming higher education.

The analytical learning demanded that our engineering students emulated what we assessed to be their current zone of proximal development (ZPD) within the social sciences and humanities. By consistently using explicit models for analytical thinking and critical reflection, we sought to develop the students' metacognition, i.e. awareness of their learning process and what they know or are capable of. By linking web forums, seminars and analytical questions it was possible to establish an 
infrastructure for student feedback where several aspects of analytical thinking were operationalized.

The course Swedish Society (SweSoc) required of students to use research of the social sciences and humanitiesto problematized topics like national identity, culture and city planning by highlighting the complexity through which these emerged historically. Although a descriptive course design might have been able to cover more content about Swedish society, e.g. history prior to the $20^{\text {th }}$ century, we argue that by using explicit models to answer analytical questions, the engineering students' developed analytical and critical skills, understanding their thinking about thinking, from which they can find out more within the social sciences and humanities long after SweSoc is finished, should they wish to. It is in the essence of analytical learning to focus not only on how students describe what they have learned, but that they can outline the merits and flaws of knowledge and how they would go about learning more.

When discussing the impact of redesigning a course towards analytical questions, critical reflections and peer-learning, these tools for transformation would need to be practiced over several semesters to assess their long-term effects. Based on the experiences from using tools of analytical models, web-based feedback and critical reflection, we identify four areas of implications of relevant for other engineering programs:

- Methodological implications

- Implications for work life skills, toolsand knowledge

- Classroom implications relating to instruction and feedback

- Implications for engineering education

Methodologically, the models and instructions for thinking, reading and writing proved successful in supporting students to demonstrate skills in analytical thinking and critical reflection. Explicit models foster explicit student feedback, though implicit elements like a text's assumptions and implications require more training.

The introduction to tools for transformation introduces and supports students in ways that improve for subsequent work life. After SweSoc, students know how to go about toindividually and continually develop skills of critical questioning and analytical 
writing also in subsequent courses and professional contexts, e.g. providing comments to drafts given by colleagues or project team members etc.

Implications relating to instruction and feedback in the classroom have to do with shifting from descriptive to analytical education and providing guides for giving instructions to seminars and course activities. For this reason, pedagogical development must look for means of constructing infrastructure by which reform can be sustained over time. Explicit models for analytical thinking and critical reflection serve as infrastructure for new generations of course coordinators and teachers to use in introducing students to social sciences and humanities. Teachers facilitating explicit models to large classes are required to rely on active student participation for their implementation.For teachers to redesign curriculum, it is imperative to do things differently rather than doing more. What can be achieved must be done so given the present amounts of time and resources available so as not to become too arduous a task to take on when shifting from descriptive to analytical education.

The above-mentioned areas of implications do, in different ways, influence engineering education as a whole. Experiences from working with methods aiming to enable students to improve analytical reading, writing and critical reflection show that social sciences and humanities scholars have a role in engineering education in providing instructions and time to practice critical and analytical thinking and reading. Moreover, results of the study show that students devote time on reading and preparing for writing when using web-based feedback in course discussion forums. From the teacher perspective, knowledge about using web-based forums and access to resources and infrastructure to do so by teachers and universities are essential for enabling student peer-learning. We also stress that it is important that study programs at university integrate ways to practice working with analytical questions and critical reflection, also by using web-based feedback, early in study programs to provide a forum for critical reflection in relation to course content throughout the engineering education.

To conclude, the implication of using analytical models, web-based feedback and critical reflection in engineering education is, on one hand, instrumental for student activation in the sense that students acquire skills for active reading and writing. In addition to this, using analytical questions and peer-comments in seminar activities 
and web forums prompt new channels for interactive learning between students and a more transformative prospect of relating both skills and knowledge from social sciences and humanitieswith engineering practices in society.

\section{Acknowledgements}

Technical solutions for web-based forums were developed with suggestions and encouragement from Anders (Ping-Pong) Ambrén. Comments received during presentation at KTH School of Education and Communication in Engineering Science 17 December 2014 are gratefully acknowledged. The authors also wish to thank participants at the pedagogical seminar 16 January 2015 for suggestions and good discussions. The authors are grateful for input to this study from colleagues who had been course responsible and seminar leaders of the course in the past, including Anders Houltz who was first course responsible and experienced a fivefold increase in the number of students between first and second semester that the course was given. A special thanks goes to ViggoKann and Arne Kaiser for comments on previous manuscripts. Lastly, credit is due to the students of the course Swedish Society whose presence at KTH help expand both the possibilities for engineering education and our conceptions of the world.

\section{References}

1. Kaijser, A., Interview with Arne Kaijser about the course Swedish Society, J.a.L. Gärdebo, Katarina, Editor. 2014: KTH Royal Institute of Technology.

2. Law, J. Working well with Wickedness. 2014; Available from: http://www.cresc.ac.uk/publications/working-well-with-wickedness.

3. Rittel, W.J.H.a.W., M. Melvin, Dilemmas in a General Theory of Planning. Policy Sciences, 1973. 4: p. 155-169.

4. SFS, Swedish Higher Education Ordinance. Annex 2. Competence and skills for a degree of Master of Science and Engineering. 1993.

5. Kaijser, A., Ingenjörer i takt med tiden?, in Vad är en ingenjör?, I.E. Björck, Editor. 1998.

6. SweSoc, Course Analysis. 2008, KTH Royal Institute of Technology: Stockholm.

7. SweSoc, Course Syllabus 4D1222. January 2007 KTH Royal Institute of Technology: Stockholm.

8. SweSoc, Course Syllabus 4D1222. September 2006 KTH Royal Institute of Technology: Stockholm.

9. Törnkvist, H., Interview with Helena Törnkvist K. Larsen, Editor. 2014: KTH Royal Institute of Technology. 
10. Avango, D., Höhler, S., Lidström, S., Pérez, I. and Petterson, I., Interviews and course analysis with Dag Avango, Sabine Höhler, Susanna Lidström, Isabel Pérez, Ingemar Pettersson, J.a.L. Gärdebo, Katarina, Editor. 2014: KTH Royal Institute of Technology.

11. Nilsson, B.a.W., A-K., Kommunikation. Samspel mellan människor [Communication. Interplay between humans]. 1994, Lund: Studentlitteratur.

12. Biggs, J.a.T., C., Teaching for Quality Learning at University, Fourth Edition. 2011: The Society for Research into Higher Education.

13. McMahon T. and Thakore, H., Achieving constructive alignment: putting outcomes first. The Quality of Higher Education, 2006. 3: p. 10-19.

14. Griffith, T., Plato: The Republic. 2000, Cambridge: Cambridge University Press.

15. Richard, P.a.E., L., A Miniature Guide For Students and Faculty To The Foundations of Analytical Thinking. How to Take Thinking Apart And What To Look For When You Do. 2005: The Foundation for Critical Thinking.

16. Richard, P.a.E., L. Elements of Analysis. 2008.

17. Lagerqvist, C., Vad är "högre" $i$ den högre utbildningen? Om den högre utbildningens kvalitativa mervärde inom historieämnet vid University of Oxford och Uppsala universitet. 2010: Uppsala University.

18. Larsen, K., Critical reflection on results in texts, in Course Material Larsen. 2014, KTH Royal Institute of Technology: Stockholm.

19. Edwards, P. How to Read a Book, v. 5.0. 2013.

20. King, A., Enhancing Peer Interaction and Learning in the Classroom Through Reciprocal Questioning. American Educational Research Journal, 1990. 27(4): p. 664-687.

21. Anderson, J.R., Reder, L. M. and Simon, H., Radical constructivism and cognitive psychology, in Brookings papers on education policy 1998. 1998, D. Ravitch.

22. Evans, C., Making Sense of Assessment Feedback in Higher Education. Review of Educational Research, 2013. 83(1): p. 70-120.

23. Hattie, J.a.T., H., The Power of Feedback. Review of Educational Research, 2007. 77(1): p. 81-112.

24. Spotify. Engineering culture. 2014; Available from: https://labs.spotify.com/2014/03/27/spotify-engineering-culture-part-1/.

25. Knight, P., and Yorke, M., Learning, Curriculum and Employability in Higher Education. 2004, London/New York: Routledge, Falmer.

26. Engels, F., Dialectics of Nature. 1925, Moscow: Foreign Languages Publishing House.

27. Vygotsky, L.S., Tool and symbol in children's development, in L.S. Vygotsky: Mind in society, V.J.-S. M. Cole, S. Scribner, \& E. Souberman, Editor. 1978, Harvard University Press.: Cambridge, MA.

28. Crain, W., Theories Of Development. Concepts and Applications. Fifth Edition ed. 2005: Pearson Education.

29. Elmgren, M., Henriksson, A-S., Universitetspedagogik. (2010), Uppsala University.

30. Gärdebo, J., Wiggberg, Mattias, (Eds.), Students, the University's Unspent Resource: Revolutionising Higher Education Through Active Student Participation. 2012: Uppsala University.

31. Harvey, L., Review of 'Students, the University's Unspent Resource: Revolutionising Higher Education Through Active Student Participation' and 
'Transcending Boundaries: How CEMUS is Changing How We Teach, Meet and Learn. Higher Education Quarterly, 2013. 67(1): p. 95-106.

32. Healey, M., Jenkins, A. and Lea, J. et al., Developing research-based curricula in college-based higher education. 2014: The Higher Education Academy.

33. Chan, A.S.a.G., H. Practicing Collaborative Digital Pedagogy to Foster Digital Literacies in Humanities Classrooms, . 2014; Available from: http://www.educause.edu/ero/article/practicing-collaborative-digitalpedagogy-foster-digital-literacies-humanities-classrooms.

34. SweSoc, Course Survey Fall 2013. 2013, KTH Royal Institute of Technology: Stockholm.

35. SweSoc, Course Survey Spring 2014. 2014, KTH Royal Institute of Technology: Stockholm.

36. Biggs, J.a.T., C., Teaching for Quality Learning at University. 2007: The Society for Research into Higher Education.

37. Niewoehner, R.J., A critical thinking model for engineering, in 2nd international CDIO Conference. 2006: Linköping. 